\title{
Nilai-Nilai Transedental Dalam Pancasila Sebagai Kepribadian Bangsa Indonesia (Perspekspektif dari Seorang Muslim)
}

\author{
Basri ${ }^{1}$, Yulia Kurniaty ${ }^{2}$, Johnny Krisnan ${ }^{3}$ \\ 1,2,3 Fakultas Hukum Universitas Muhammadiyah Magelang, Magelang, Indonesia. \\ @ : basri@ummgl.ac.id 1,yuliakurniaty@ummgl.ac.id ${ }^{2}$, johnykrisnan@ummgl.ac.id ${ }^{3}$ \\ dol : $x x x x x x x x x x x x x x x x$
}

Info Artikel
Keywords:
Pancasila Values;
Personality; Indonesian
Nation.

Kata Kunci:

Nilai-Nilai Pancasila;

Kepribadian; Bangsa

Indonesia

\begin{abstract}
Introductioan: If we dig deeper, there is a compatibility between Islamic teachings and the values of Pancasila.

Purposes of the Research: This study aims to analyze and discuss perspectives and attitudes in the context of Pancasila values that are practiced in social life.

Methods of the Research: Answering the problems raised in this paper, the author conducts a literature study and observes what happens in social life.

Results of the Research: The results of the study show that there is no longer any reason to contradict the teachings of Islam and Pancasila. The values of Pancasila are colored by the teachings of Islam itself and it is possible that the values of Pancasila are derived from Islamic teachings. Therefore, for Muslims, there is no need to question Pancasila as the basic philosophy of the Indonesian nation and state. For others, when there is a reaction from Muslims, for example there is an issue to replace Pancasila with another ideology, there is no need to react excessively, because it cannot happen and be carried out by Muslims. Such an attitude is basically just a reaction to what happened, where some Muslims are seen as contradicting the values of Pancasila as the personality of the Indonesian nation.
\end{abstract}




\section{Pendahuluan}

Dilihat dari judul tulisan ini mungkin semua anak bangsa Indonesia sepakat dan setuju untuk menyatakan bahwa kepribadian bangsa Indonesia adalah Pancasila, atau setidak-tidaknya kepribadian bangsa Indonesia sesuai dengan nilai-nilai Pancasila. Tentu pendapat ini bukan tanpa alasan, karena memang kepada setiap anak bangsa sejak mulai sekolah sudah dikenalkan dan diajarkan oleh para guru di Sekolah, sehingga mereka hafal. Jadi Pancasila sebagai kepribadian bangsa Indonesia adalah sebuah hafalan yang diajarkan di sekolah. Akan tetapi dilihat dari realitas terasa ada kejanggalan dalam kehidupan bangsa Indonesia di era sekarang. Sehingga rasanya sangat sulit untuk menyimpulkan bahwa kepribadian bangsa Indonesia adalah Pancasila. Ada banyak alasan tentunya yang dapat dikemukakan, diantaranya kehidupan toleransi antar anak bangsa saat ini agak terganggu, rasa persatuan dan kesatuan sudah mulai goyah, slogan gotong royong tidak lagi menjadi kekuatan, Bhinneka Tunggal Ika hanya sebuah hafalan saja yang tidak pernah dipahami maknanya, dan tentu banyak alasan yang lainnya yang dapat dikemukakan.

Sungguhpun fakta saat ini yang terjadi bertolak belakang dengan nilai-nilai Pancasila, penulis masih tetap berkeyakinan bahwa Pancasila adalah memang kepribadian bangsa Indonesia. Kepribadian itu sudah ada, dikenal dan dipraktekkan dalam kehidupan oleh nenek moyang bangsa Indonesia sejak dahulu kala. Kemudian oleh pendiri bangsa Indonesia dirumuskannya dalam istilah Pancasila. Perumusan dalam istilah Pancasila tentu sudah melalui proses pemikiran dan perenungan yang panjang dan mendalam. Sedangkan apa yang terjadi saat ini menurut pemahaman penulis adalah sebuah keingkaran saja terhadap nilai-nilai Pancasila itu sendiri, di mana pada dasarnya masih diakui sebagai pandangan hidup bangsa Indonesia. Fakta ini tentu banyak hal yang melatar belakangi, salah satu menurut penulis adalah faktor politik yang belum dewasa untuk mengantarkan anak bangsa Indonesia untuk bisa berpikir secara objektif tentang dirinya dan kebangsaannya.

Faktor politik telah mengajarkan anak bangsa kearah berpikir yang pragmatis. Makna tentang persatuan dan kesatuan tidak lagi menjadi prioritas. Politik saat ini hanya mengajarkan kepada kepentingan dan kekuasaan. Politik yang sarat dengan kepentingan dan kekuasaan telah menjadikan anak bangsa sebagai objek, yang membuatnya terkotakkotak. Hal ini bisa terjadi karena isu yang diangkat oleh para politikus hanya bersifat populer, tanpa mempertimbangkan rasa kebersamaan dan persaudaraan yang telah terjalin berurat berakar dalam kesadaran anak bangsa. Isu yang diangkat para politikus telah menggoyakan semuanya itu. Jadi permasalahannya bukan dari masyarakat pada umumnya, tetapi para elit politik sebagai penyebabnya, yang barangkali tidak menyadari bahwa isu-isu yang dia lontarkan memang menguntungkan untuk kelompok dia, tetapi berbahaya dalam menjaga keutuhan, kesatuan dan persatuan bangsa.

Tulisan ini mencoba untuk meluruskan cara pandang dan prasangka itu, agar Pancasila benar-benar dipahami dan digambarkan sebagai kepribadian bangsa Indonesia. Di sini penulis memahaminya sebagai seorang Muslim, yang mencintai bangsa Indonesia dan sekaligus juga mencintai anak bangsa, siapapun dia. Dalam pemahaman ini Pancasila 
dijadikan nilai-nilai di dalam menjalin interaksi antara anak bangsa yang berbeda-beda, suku, agama, ras, dan golongan. Artinya perbedaan bukanlah alasan untuk bercerai berai, tetapi perbedaan semestinya dijadikan alat untuk memperkuat persatuan dan kesatuan bangsa.

\section{Metode Penelitian}

Dalam menjawab persoalan yang dikemukakan dalam tulisan ini, penulis melakukan studi literatur dan melakukan pengamatan terhadap apa yang terjadi dalam kehidupan bermasyarakat. Dalam hal ini penulis membagi masyarakat ke dalam dua kelompok, yaitu masyarakat kota dan masyarakat desa. Menurut penulis penting untuk membedakan dua kelompok ini untuk melihat cara pandang dan sikap mereka dalam kehidupan sehari-hari. Di sini penulis akan melihat cara pandang dan sikap mereka dalam konteks nilai-nilai Pancasila yang dipraktekkan dalam kehidupan bermasyarakat. Sungguhpun demikian nilai-nilai Pancasila yang dimaksudkan di sini adalah yang sesuai dengan pemahaman penulis sebagai seorang Muslim. Barangkali bisa jadi dinilai sangat subjektif, walaupun demikian penulis berupaya agar bisa menampilkannya secara objektif, dalam arti nilai-nilai yang dikembangkan bisa dipakai dalam kehidupan bersama, dalam perbedaan suku, ras, dan agama yang ada di Indonesia.

\section{Hasil dan Pembahasan}

Sejak awal kemerdekaan, terutama saat penyusunan konstitusi negara, telah muncul bibit antagonisme hubungan politik khususnya antara Islam dan negara ${ }^{1}$. Berpikir seperti ini adalah dalam konteks masyarakat kota, yang lebih mendahulukan persoalan politik. Walaupun sebagian pakar ada yang menganggap persoalan ini tidak perlu dihidupkan lagi, karena dianggap sebuah pertarungan ideologis yang telah usang ${ }^{2}$ diperdebatkan. Namun penulis masih merasa penting untuk memperdebatkan, karena persoalan ini sampai sekarang masih sering muncul kepermukaan. Menjadi isu yang menarik bagi kalangan politikus. Sementara dalam kehidupan masyarakat dipedesaan biasa-biasa saja. Mereka seoalah-olah tidak terpengaruh dengan hiruk pikut para politikus yang hidup di kota. Mereka menjalani kehidupan dalam suasana kebersamaan di dalam perbedaan. Hidup dalam gotong-royong dan saling peduli satu sama lain selalu di bangun.

Hiruk pikuk para politikus membawa penulis pada pemikiran bahwa seolah-olah Pancasila sebagai dasar negara masih belum selesai untuk diperdebatkan dan terkesan masih dipertentangkan. Sebenarnya menurut pandangan penulis secara pribadi, Pancasila sebagai dasar negara memang tidak perlu diperdebatkan lagi, karena Pancasila telah diyakini sebagai kepribadian bagi seluruh anak bangsa Indonesia. Artinya Pancasila merupakan suatu kenyataan objektif yang hidup dan berkembang dalam masyarakat Indonesia. ${ }^{3}$ Istilah Pancasila diusulkan oleh Ir. Soekarno pada Sidang Pertama BPUPKI hari

${ }^{1}$ Basri and Budiharto, “Agama Sebagai Dasar Fundamental Dalam Negara Pancasila," Pelita Bangsa Pelestari Pancasila 15, no. 1 (2020): 22-37.

2 Maarif Ahmad Syafii, Islam Dan Pancasila Sebagai Dasar Negara (Bandung dan Jakarta: Mizan Pustaka dan Maarif Institute For Culture and Humanity, 2017), h. ix.

${ }^{3}$ Kaelan, Filsafat Pancasila Pandangan Hidup Bangsa Indonesia (Yogyakarta: Paradigma, 2009), h. 1. 
terakhir tanggal 1 Juni 1945. Menurut pengakuan beliau istilah Pancasila diberikan adalah atas dasar petunjuk seorang ahli Bahasa, ada dugaan beliau adalah Muhammad Yamin.

Istilah Pancasila sebagai kepribadian bangsa adalah merujuk kepada pengertian identitas. Hendrizal ${ }^{4}$ mengatakan Identitas suatu bangsa tidak dapat dipisahkan dengan jati diri bangsa tersebut atau lebih populer disebut sebagai kepribadian suatu bangsa. Lebih lanjut Hendrizal ${ }^{5}$ mengemukakan bahwa kepribadian sebagai identitas nasional suatu bangsa adalah keseluruhan atau totalitas dari kepribadian individu-individu sebagai unsur yang membentuk bangsa tersebut. Oleh karena itu pengertian identitas nasional suatu bangsa tidak dapat dipisahkan dengan pengertian "peoples character", "national carachter" atau "national identity".

Identitas merupakan sesuatu yang dikonstruksi oleh masyarakat untuk memberi makna pada kehidupannya. Ketika ditarik ke tingkat nasional, negara mengonstruksi identitas bangsa (identias nasional). ${ }^{6}$ Identitas nasional (bangsa) adalah ungkapan nilai budaya suatu masyarakat atau bangsa yang bersifat khas yang membedakannya dengan bangsa lain. ${ }^{7}$ Pancasila adalah identias nasional bangsa Indonesia. Kaelan mengatakan bangsa Indonesia adalah kausa materialis dari Pancasila ${ }^{8}$.

Kaelan menegaskan: Secara historis bahwa nilai-nilai yang terkandung dalam setiap sila Pancasila sebelum dirumuskan dan disahkan menjadi dasar negara Indonesia secara objektif historis telah dimiliki oleh bangsa Indonesia sendiri sehingga asal nilai-nilai Pancasila tersebut tidak lain adalah dari bangsa Indonesia sendiri, atau dengan kata lain bangsa Indonesia sebagai kausa materialis Pancasila. Oleh karena itu berdasarkan fakta objektif secara historis kehidupan bangsa Indonesia tidak dapat dipisahkan dengan nilainilai Pancasila9.

Berpijak dari pendapat Kaelan, penulis mencoba untuk menemukan nilai-nilai tersebut dari perspektif sebagai seorang Muslim. Dalam hal ini tentu sumber dasar ajaran Islam yang menjadi acuan utama bagi penulis. Untuk itu perlu penulis tekankan, adalah berbeda antara sebagai seorang Muslim dengan sumber dasar ajaran Islam. Seorang Muslim bisa saja melakukan kesalahan atau menyimpang dari ajaran Islam. Oleh karena itu, maka di dalam menilai kesesuaian antara Pancasila dengan ajaran Islam perlu dilihat pada ajaran Islam itu sendiri, bukan melihat pada umatnya. Umat Islam bisa jadi ada yang baik dan ada yang kurang baik. Di sisi lain, andaikata ada sekelompok umat Muslim yang menyuarakan tentang negara Islam, tentu hal ini patut dipahami sebagai reakasi atau anti tesa terhadap fakta yang terjadi di dalam bernegara dan berbangsa Indonesia. Untuk itu tidak perlu disikapi secara berlebihan, apalagi dengan memusuhi umat Muslim. Jika sikap seperti ini dilakukan, maka selamanya isu ini akan selalu muncul dan bergelora. Di sini penulis ingin

\footnotetext{
${ }^{4}$ Hendrizal, “Mengulas Identitas Nasional Bangsa Indonesia Terkini. Pelita Bangsa Pelestari Pancasila," Pelita Bangsa Pelestari Pancasila 15, no. 1 (2020): 1-21.

5 Ibid.

${ }^{6}$ A Safril Mubah, "Revitalisasi Identitas Kultural Indonesia Di Tengah Upaya Homogenisasi Global," Global \& Strategis Edisi Khusus, no. Desember (2011): 251-60.

7 Akhmad Yazidi, "Bahasa Indonesia Sebagai Identitas Nasional Bangsa Indonesia (Indonesian Language As The National Identity Of Indonesian)," Jurnal Bahasa E Sastra 2, no. 2 (2012): 163-77.

8 Kaelan, Filsafat Pancasila Pandangan Hidup Bangsa Indonesia. Op. Cit. h. 1.

${ }^{9}$ Ibid. h. 12.
} 
menekankan, cobalah bersifat bijak, dan tentu juga adil dengan umat Islam. Bagaimanapun juga di negara yang kita cintai ini, 2/3 adalah umat Islam.

Pancasila sebagai sumber hukum negara maka Pancasila memiliki fungsi sebagai bintang pemandu dalam pembentukan produk hukum nasiona ${ }^{10}$. Rumusan Pancasila dimuat di dalam Pembukaan Undang-Undang Dasar 1945. Menurut Kabul Budiyono pertama-tama adalah dimaksudkan sebagai Dasar Negara yang mempunyai predikat atau kualifikasi sebagai Dasar Filsafah Negara (Philosophiche-Grondslag). Sebagai Dasar Filsafat Negara, maka: (1) sila-sila Pancasila merupakan suatu kesatuan yang bulat dan utuh; (2) Sila-sila Pancasila merupakan suatu susunan yang bertingkat (hierarkhissistematis), dan (3) hubungan timbal balik antara sila-sila Pancasila. ${ }^{11}$

Sila-sila Pancasila sebagai satu kesatuan yang bulat dan utuh mengandung pengertian sila-sila tersebut saling terkait dan tidak dapat dipisahkan. Sila-sila Pancasila merupakan susunan yang bertingkat mengandung pengertian bahwa kelima sila-sila, yaitu mulai dari Ketuhanan Yang Maha Esa sampai dengan sila Keadilan Sosial Bagi Seluruh Rakyat Indonesia menunjukkan suatu rangkaian urut-urutan yang bertingkat-tingkat. Kemudian tentang hubungan timbal balik antara sila-sila Pancasila mengandung makna bahwa sila Ketuhanan Yang Maha Esa menjiwai dan meliputi sila Kemanusiaan Yang Adil dan Beradab, sila Persatuan Indonesia, Sila Kerakayatan Yang Dipimpin Oleh Hikmah Kebijaksanaan Dalam Permusyawaratan Perwakilan dan sila Keadilan Bagi Seluruh Rakyat Indonesia, dan begitu sebaliknya, sehingga saling berhubungan.

Konsep ajaran Islam, misalnya tentang sila Ketuhanan Yang Maha Esa dapat dilihat dalam Al-Qur'an Surat Al-Ikhlas (112), ayat 1, yang artinya: “Katakanlah Muhammad, "Dialah Allah, Yang Maha Esa". Ini apa artinya? Ternyata ada kesesuaian antara ajaran Islam dengan sila pertama, "Ketuhanan Yang Maha Esa". Jika demikian halnya maka dapat ditafsirkan bahwa tidak ada perbedaan antara ajaran Islam dengan sila pertama Pancasila. Ajaran ini tentu menjadi sumber utama bagi seorang Muslim di dalam menjalankan ajaran agama Islam. Andaikata ada keinginan dari sebagian umat Islam untuk menyatakan kembali kepada syariat, atau katakanlah ada keinginan untuk mendirikan negara Islam tentu maksudnya adalah kembali kepada ajaran Allah Yang Maha Esa, yang di dalam sila pertama dirumuskan dalam kalimat Ketuhanan Yang Maha Esa. Lebih jauh dari ini tentu perlu dilihat faktor apa yang menjadi pendorong, sehingga sebagian umat Muslim berkeinginan kepada yang demikian itu. Tentu ada hal yang dianggapnya menyimpang dari nilai-nilai Ketuhanan Yang Maha Esa. Oleh karena itu rasanya tidak perlu ada pernyataan-pernyataan negatif, apalagi memusuhi umat Islam. Jika ini dilakukan maka selamanya negara yang kita cintai ini tidak akan damai, kita hanya sibuk mempersoalkan hal yang sudah jelas menjadi kepribadian bangsa Indonesia, yaitu bangsa yang Bertuhan kepada Tuhan Yang Maha Esa.

Bagaimana implementasinya dalam kaitannya dengan agama lain, ajaran Ketuhanan Yang Maha Esa ini. Tentang hal ini misalnya dapat dilihat ajaran agama Islam dalam surat Al-Kafirun (109), ayat ke-6, yang artinya: “Untukmu agamamu, dan untukku agamaku”.

10 Madaskolay Viktoris Dahoklory and Lita Tyesta Addy Listya Wardhani, "Rekonstruksi Nilai-Nilai Pancasila Dalam Undang-Undang," SASI 26, no. 3 (2020): 297-309.

${ }^{11}$ Kabul Budiyono, Pendidikan Pancasila Untuk Perguruan Tinggi (Bandung: Alfabeta, 2016), h. 39-43. 
Jadi dalam ajaran ini terkandung makna untuk saling mengakui agama masing-masing. Adanya pengakuan berarti akan lahir sikap saling menghormati satu sama lain.

Berikutnya tentang sila kedua, Kemanusiaan Yang Adil dan Beradab. Dalam ajaran Islam sangat banyak berbicara tentang nilai-nilai kemanusiaan, nilai keadilan, dan beradab, diantaranya dapat dilihat dalam Al-Qur'an Surat Al-Hujarat, ayat 13, yang artinya: "Hai manusia, sesungguhnya Kami menciptakan kamu dari seorang laki-laki dan seorang perempuan dan menjadikan kamu berbangsa-bangsa dan bersuku-suku supaya kamu saling kenal mengenal. Sesungguhnya orang yang paling mulia di antara kamu di sisi Allah ialah orang yang paling bertakwa di antara kamu. Sesungguhnya Allah Maha Mengetahui lagi Maha Mengenal." Jadi tidak ada permasalahan dengan adanya perbedaan menurut ajaran Islam. Perpedaan adalah kurniah, lumrah dan fitrah. Untuk itu andaikata hal ini menjadi masalah dalam kehidupan kenegaraan dan kebangsaan Indonesia, tentu perlu dicari jawaban yang objektif tentang masalah ini. Tentu tidak bijak jika disikapi dengan sikap arogan pada suatu kelompok atau agama tertentu. Dari sekarang mari dihindari katakata yang bersifat adu domba, provokatif dan saling merendahkan. Karena sikap yang suka mengadu domba bukanlah kepribadian bangsa Indonesia.

Sikap adil yang tertuang dalam Pancasila seharusnya diterapkan dalam menyelesaikan permasalahan berbagai permasalah yang muncul ${ }^{12}$. Al-Qur'an surat AnNahl ayat 90, juga dapat dijadikan ajaran tentang nilai-nilai kemanusiaan yang harus dipedomani umat Muslim, adapun terjemahannya berbunyi: "Sesungguhnya Allah menyuruh manusia berlaku adil dan berbuat kebaikan, memberi sedekah kepada kaum kerabat, dan Allah melarang dari perbuatan keji, kemungkaran, dan permusuhan. Dia memberi pengajaran kepadamu (manusia), agar kamu dapat mengambil pelajaran". Kemudian tentang sila "Persatuan Indonesia". Banyak sekali ajaran Islam mengajarkan tentang pentingnya persatuan dan kesatuan, diantaranya ditegaskan dalam Al-qur' an Surat Al-Hujarat, ayat 10, yang artinya: "Sesungguhnya orang-orang mukmin adalah bersaudara karena itu damaikanlah antara kedua saudaramu dan bertakwalah kepada Allah supaya kamu mendapat rahmat." Artinya orang-orang mukmin dilarang untuk saling bermusuhan, dan jika ada yang saling bermusuhan maka Muslim yang lainnya wajib mendamaikannya. Inilah adalah ajaran Islam yang semestinya dijalankan dalam kehidupan berbangsa dan bernegara. Sila keempat, "Kerakyatan Yang Dipimpin Oleh Hikmat Kebijaksanaan Dalam Permusyawaratann/Perwakilan. Dalam ajaran Islam dapat dilihat dalam Al-Qur'an Surat As-Syuro ayat 38, yang artinya: “Dan bagi orang-orang yang menerima (mematuhi) seruan Rabb-nya, dan mendirikan shalat, sedang urusan mereka (diputuskan) dengan musyawarah antara mereka; dan mereka menafkahkan sebagian dari rejeki, yang Kami berikan kepada mereka". Ajaran seperti ini nampaknya banyak dipraktekkan dalam kehidupan masyarakat kita di pedesaan. Biasanya mereka dalam hal ada hajatan misalnya, akan dimulai dengan duduk bersama untuk musyawarah, dengan mengajak orang lainnya untuk ikut terlibat dalam pelaksanaan hajatan tersebut.

Terakhir sila kelima, Keadilan Sosial Bagi Seluruh Rakyat Indonesia". Nilai-nilai ajaran Islam kaitan dengan ini, misalnya dapat dilihat dalam Al-qur'an Surat An-Nisa, ayat

12 Mustaqim and Agus Satory, "Perlindungan Hukum Pemegang Saham Minoritas Perseroan Terbatas Tertutup Dan Keadilan Berdasar Pancasila," SASI 25, no. 2 (2019): 199-210. 
135, yang artinya: "Wahai orang-orang yang beriman, jadilah kamu penegak keadilan, menjadi saksi karena Allah walapun terhadap dirimu sendiri atau terhadap ibu bapak dan kaum kerabatmu. Jika dia (yang terdakwa) kaya ataupun miskin, maka Allah lebih tahu kemaslahatan (kebaikannya). Maka janganlan kamu mengikuti hawa nafsu karena ingin menyimpang dari kebenaran, dan jika kamu memutar balikan (kata-kata) atau enggan menjadi saksi, maka ketahuilah Allah Maha Teliti terhadap apa yang kamu kerjakan".

\section{Kesimpulan}

Ajaran Islam yang penulis kemukakan di atas baru hanya beberapa ayat yang ditampilkan dari ribuan ayat yang ada dalam Al-Qur'an. Tentu sangat banyak ayar-ayat AlQur'an yang mengajarkan nilai-nilai yang harus dijadikan pedoman di dalam menjalankan kehidupan bernegara dan berbangsa bagi bangsa Indonesia. Dengan berpedoman kepada beberapa ayat tersebut, tentu tidak dapat untuk mengatakan bahwa ajaran Islam bertentangan dengan nilai-nilai Pancasila, bahkan bisa jadi nilai-nilai Islam memberi warna terhadap nilai-nilai yang dikembangkan dalam Pancasila. Ajaran Islam tentu sudah semestinya menjadi kepribadian bagi seorang Muslim. Sekarang sudah menjadi tugas kita sebagai anak bangsa untuk menjelaskan bagaimana sesungguhnya ajaran Islam itu, dalam kerangka hidup bernegara dan berbangsa. Sehingga kehidupan "Baldatun Thoyibatun warobbun Ghofur", benar-benar dirasakan dalam kehidupan berbangsa dan bernegara Indonesia.

\section{Referensi}

Basri, and Budiharto. “Agama Sebagai Dasar Fundamental Dalam Negara Pancasila." Pelita Bangsa Pelestari Pancasila 15, no. 1 (2020): 22-37.

Budiyono, Kabul. Pendidikan Pancasila Untuk Perguruan Tinggi. Bandung: Alfabeta, 2016.

Dahoklory, Madaskolay Viktoris, and Lita Tyesta Addy Listya Wardhani. "Rekonstruksi Nilai-Nilai Pancasila Dalam Undang-Undang." SASI 26, no. 3 (2020): 297-309.

Hendrizal. “Mengulas Identitas Nasional Bangsa Indonesia Terkini. Pelita Bangsa Pelestari Pancasila." Pelita Bangsa Pelestari Pancasila 15, no. 1 (2020): 1-21.

Kaelan. Filsafat Pancasila Pandangan Hidup Bangsa Indonesia. Yogyakarta: Paradigma, 2009.

Mubah, A Safril. "Revitalisasi Identitas Kultural Indonesia Di Tengah Upaya Homogenisasi Global." Global \& Strategis Edisi Khus, no. Desember (2011): 251-60.

Mustaqim, and Agus Satory. "Perlindungan Hukum Pemegang Saham Minoritas Perseroan Terbatas Tertutup Dan Keadilan Berdasar Pancasila." SASI 25, no. 2 (2019): 199-210.

Syafii, Maarif Ahmad. Islam Dan Pancasila Sebagai Dasar Negara. Bandung dan Jakarta: Mizan Pustaka dan Maarif Institute For Culture and Humanity, 2017.

Yazidi, Akhmad. "Bahasa Indonesia Sebagai Identitas Nasional Bangsa Indonesia (Indonesian Language As The National Identity Of Indonesian)." Jurnal Bahasa $\mathcal{E}$ Sastra 2, no. 2 (2012): 163-77. 